\title{
Trabalho-Educação no Estado-finanças
}

\author{
Work-Education in the State-finance \\ Trabajo-Educación en el Estado-finanzas
}

Recebido: 11/01/2022 | Revisado: 15/01/2022 | Aceito: 21/01/2022 | Publicado: 23/01/2022

\author{
Amanda Melchiotti Gonçalves \\ ORCID: https://orcid.org/0000-0002-8600-6248 \\ Universidade Estadual do Oeste do Paraná, Brasil \\ E-mail: amandamelchiottigoncalves@gmail.com \\ Roberto Antonio Deitos \\ ORCID: https://orcid.org/0000-0001-9150-6354 \\ Universidade Estadual do Oeste do Paraná, Brasil \\ E-mail: rdeitos@uol.com.br \\ João Batista Zanardini \\ ORCID: https://orcid.org/0000-0002-1514-6489 \\ Universidade Estadual do Oeste do Paraná, Brasil \\ E-mail: j.zanardin@uol.com.br \\ Dhyovana Guerra \\ ORCID: https://orcid.org/0000-0002-1026-606X \\ Universidade Estadual do Oeste do Paraná, Brasil \\ E-mail: dhyovanaguera@hotmail.com
}

\begin{abstract}
Resumo
$\mathrm{O}$ artigo tem como objetivo refletir algumas proposições da dinâmica do Estado-finanças com base na premissa indissociável do sistema capitalista: "Trabalho-Educação". Fundamenta-se, para tanto, no pressuposto de que o Estadofinaças faz parte do desenvolvimento histórico e social do modo de produzir capitalista, sendo produto das relações humanas sobre a natureza. Assim, as contradições do sistema financeiro evidenciam disfunções no processo socioeconômico e, como consequência, os efeitos do avanço tecnológico e o retrocesso das circuntâncias laborais na finança globalizada são mistificados e a Teoria do Capital Humano para a educação se torna o subsídio da configuração do modus operandi do capital portador de juros por meio de orientações e diretrizes dos organismos internacionais que assentem para uma concepção empreendedora a partir de soluções privadas, no âmbito da gestão e dos processos educativos. É por isso que a formação educativa com base em competências socioecmocionais se alinha a "nova" investida dos empreendedores educacionais, haja vista que essa é capaz de resignar os indivíduos para as condições do trabalho assalariado cada vez mais flexível e precarizado.
\end{abstract}

Palavras-chave: Estado-finanças; Capital portador de juros; Trabalho-educação.

\begin{abstract}
The article aims to reflect some propositions of the State-finance dynamics based on the inseparable premise of the capitalist system: "Work-Education". It is based, therefore, on the assumption that the State-finance is part of the historical and social development of the capitalist way of producing, being a product of human relations on nature. Thus, the contradictions of the financial system show dysfunctions in the socioeconomic process and, as a consequence, the effects of technological advancement and the setback of labor circumstances in globalized finance are mystified and the Human Capital Theory for education becomes the subsidy for the configuration of the modus operandi of interestbearing capital through guidelines and directives from international organizations that are based on an entrepreneurial concept based on private solutions, within the scope of management and educational processes. That is why educational training based on socio-emotional skills aligns with the "new" onslaught of educational entrepreneurs, given that this is capable of resigning individuals to the conditions of increasingly flexible and precarious salaried work.
\end{abstract}

Keywords: State-finance; Interest-bearing capital; Work-education.

\section{Resumen}

El artículo pretende reflejar algunas proposiciones de la dinámica Estado-finanzas a partir de la premisa inseparable del sistema capitalista: “Trabajo-Educación". Se fundamenta, por tanto, en el supuesto de que el Estado-financiero forma parte del desarrollo histórico y social de la forma capitalista de producir, siendo producto de las relaciones humanas sobre la naturaleza. Así, las contradicciones del sistema financiero muestran disfunciones en el proceso socioeconómico $\mathrm{y}$, en consecuencia, se mistifican los efectos del avance tecnológico y el retroceso de las circunstancias laborales en las finanzas globalizadas y la Teoría del Capital Humano para la educación se convierte en el subsidio para la configuración del modus operandi del capital rentable a través de lineamientos y directivas de organismos internacionales que se fundamentan en un concepto empresarial basado en soluciones privadas, en el ámbito de los procesos de gestión y 
educación. Es por ello que la formación educativa basada en competencias socioemocionales se alinea con la "nueva" embestida de los emprendedores educativos, dado que ésta es capaz de resignar a los individuos a las condiciones de un trabajo asalariado cada vez más flexible y precario.

Palabras clave: Estado-finanzas; Capital que devenga intereses; Trabajo-educación.

\section{Introdução}

O Estado-finanças ${ }^{1}$ é a composição do establishment capitalista atual. Sua dinâmica faz parte do desenvolvimento histórico e social do modo de produzir capitalista, todavia, vale lembrar que sua constituição é produto das relações humanas sobre a natureza. A incorporação da finança mundializada corresponde, em grande medida, a apropriação capitalista em função das demandas de sua própria dinâmica de acumulação. Isso quer dizer que as relações sociais no Estado-finanças são mediadas pelo capital portador de juros por meio de intermediações ancoradas pelo gerenciamento, financiamento e o endividamento da esfera pública, possibilitando mediações que geram fluidez para o estabelecimento de organizações financeiras e parcerias público-privadas no processo de circulação do capital.

No mundo capitalista avançado ocorrem algumas contradições intrínsecas ao seu sistema, ou seja, a sofisticação da vida social e das instituições que gerenciam os fluxos do capital portador de juros produzem consequências que se caracterizam pelo ininterrupto processo circular e destrutivo do desenvolvimento socioeconômico (Mészáros, 2011a). Nesse sentido, o lócus deste texto é refletir alguns aspectos da dinâmica do Estado-finanças com base na premissa indissociável do sistema capitalista: "Trabalho-Educação"2.

\section{Metodologia}

Este texto é de caráter bibliográfico de abordagem qualitativa (Severino, 2016). Tem como referências os autores: Antunes (2020); Banco Mundial (2018); Chesnais (2005); Duménil e Lévy (2005); Fatorelli (2013); Fatorelli (2019); Freitas (2018); Gramsci (1982); Autor (2021); Harvey (2016); Harvey (2018); Harvey (2014); Mészáros (2011a); Mészáros (2011b); Ramos (2001); Williamson (1991). Como referencial de análise da realidade, apoia-se em Evangelista (2012) e Shiroma et al. (2005) que ressaltam a necessidade de uma análise crítica da realidade, a fim de compreender e intervir sobre ela. Na mesma direção, apreender a totalidade não significa conhecer totalmente a realidade, mas compreender que os fatos existem em conjunto, de modo não linear e, portanto, é apenas nesse conjunto que podem ser compreendidos. Portanto, a seleção dos textos que compõem as reflexões deste artigo faz parte de uma consciência social de realidade a partir de uma totalidade histórica em conexão com as esferas da vida social e estabelece, assim, uma práxis $^{3}$ com as condições históricas que formam a consciência do ser social.

\section{Resultados e Discussão}

\section{Trabalho-Educação no Estado-finanças: efeitos socioeconômicos e políticos}

O Estado-finanças, especialmente após a década de 1980 e 1990, estrutura-se pelo tripé da liberalização, desregulamentação e privatização (Williamsom, 1991). Essa configuração sistêmica é elemento-chave para a compreensão da dinâmica financeira que tem como base a premissa "Trabalho-Educação".

\footnotetext{
1 Para Harvey (2014), a economia mundial está situada no plano da economia de crédito e sua estrutura é a associação entre Bancos centrais mundiais e autoridades reguladoras estatais, constituindo-se, assim, o Estado-finanças.

2 "A importância da relação trabalho-educação se justifica porque justamente a partir dela a formação humana configura-se como processo contraditório e marcado pelos valores capitalistas." (Ramos, 2001, p. 29).

${ }^{3}$ A relação entre teoria e práxis é para Marx teórica e prática; prática, na medida em que a teoria, como guia da ação, molda a atividade do homem, particularmente a atividade revolucionária; teórica, na medida em que esta relação é consciente. (Vásquez, 2011, p. 111)
} 
Em âmbito global, o regime de acumulação financeira propicia uma concentração de riquezas aos países considerados centrais e ou avançados, além de afirmar a concepção hegemônica em relação aos outros países, a exemplo dos Estados Unidos da América (EUA) ${ }^{4}$. O capital portador de juros está imbuído nas formas de grupos industriais transnacionais, instituições financeiras bancárias e não bancárias, esses, por sua vez, atuam nos lucros mediante especulação. No entanto, como destaca Harvey (2018), compreender o capital financeiro enquanto valor em movimento, implica em integrar a análise não só pela mediação do mercado, mas também pelo poder do Estado como condição e mediação superestrutural do sistema capitalista.

A intensificação das políticas neoliberais, alicerces da financeirização, abrem caminho para a potencialização da flexibilização, desregulamentação do trabalho e falta de proteção social em prol de um suposto crescimento sem precedentes. O capital portador de juros, segundo Chesnais (2005), demanda da economia "mais do que ela pode dar" e nessa "insaciabilidade" ocorrem as desregulamentações do trabalho, bem como as privatizações para que os tratados como "inadequados" se reordenem de acordo com a lógica econômica existente de intensificação de processos de expropriação, exploração e acumulação em escala explosiva.

Aos tratados como inadequados, mais conhecidos como países de Terceiro Mundo ou Subdesenvolvidos ${ }^{5}$, cabe a consequência desse sistema que produz crises não só financeiras, mas sociais, ambientais, alimentares, etc. Esse sistema acarreta aos países uma dominação política e social, assim, a extrema concentração de riquezas dos países centrais do sistema financeiro representa também a acumulação do poder político e a consequente dominação socioeconômica, financeira e militar como uma dominação sistêmica e estrutural.

Com a expansão do sistema financeiro, a América Latina se orienta de acordo com o receituário de medidas de "avanço" e "desenvolvimento" da globalização. Os mecanismos de liberalização e desregulamentação nesses países levam ao processo de dívida pública sem contrapartida, uma vez que os empréstimos ou créditos destinados, principalmente pelo Fundo Monetário Internacional (FMI) e Banco Mundial, não possuem a entrega efetiva desses recursos ou os encargos e juros transformam as dívidas em dívidas impagáveis, insaciáveis e violentamente lucrativas para os polos de acumulação dirigidos pelos países e empresas transnacionais econômicas e financeiras hegemônicas globalmente. Tais empréstimos ou créditos, conforme Fattorelli (2013), caracterizam-se pela transferência de recursos para megaprojetos superfaturados ou mesmo ao financiamento de ditaduras militares que ocorreram em diversos países da região ${ }^{6}$.

O Sistema da Dívida Pública, aliado ao processo de privatização dos serviços estatais, é o condão de sustentamento dos mercados financeiros. O sistema de autogeração do endividamento público ${ }^{7}$ passa a ser pago com novos empréstimos ou créditos, aumentando o montante da dívida, que em geral, não promove benefícios aos países. Como consequência, para Millet e Toussaint (2006), os países que decidem atender às exigências do FMI e do Banco Mundial, além de outros credores, não possuem outra alternativa a não ser implementar uma política rigorosa de austeridade fiscal “[ [...] o que implica a redução máxima das despesas públicas na área da educação, saúde, da manutenção das infraestruturas, do investimento público nas atividades geradoras de emprego, da habitação, para não falar da pesquisa e da cultura.” (Millet; Toussaint, 2006, p. 44). Entretanto, os efeitos do sistema financeiro são escamoteados na forma de crescimento harmonioso e sustentável.

\footnotetext{
${ }^{4}$ Isso não quer dizer que não há a preponderância de outros grandes países no sistema financeiro. "Note-se que o imperialismo não é constituído por um país, mas por um conjunto de países. Estes estabelecem relações de luta, indo até o confronto armado entre duas potências. Cada estado aí representa os interesses de suas classes dominantes. Um país pode ocupar uma posição hegemônica, como os Estados Unidos, que dirigem, no mundo contemporâneo unipolar, a coalizão imperialista. Dessa maneira, a relação de dominação se estabelece em dois níveis: entre o país dominante e os outros membros da coalizão e entre essa coalizão imperialista e os outros países dominados.” (Duménil \& Lévy, 2005, p. 93).

${ }^{5}$ Os efeitos do sistema financeiro são sentidos no mundo todo. Porém, nos países onde ocorre uma dependência macroeconômica, seus efeitos são ainda mais dramáticos.

${ }^{6}$ Guatemala, Paraguai, Argentina, Brasil, Peru, Uruguai, Chile, República Dominicana, Nicarágua, Bolívia, Brasil.

7 “[...] Os juros devidos sobre o principal da dívida (o serviço da dívida) absorvem uma fração sempre maior do orçamento do Estado, das receitas das exportações e das reservas do país, de sorte que a única maneira de fazer face aos compromissos do serviço da dívida é tomar um novo empréstimo.” (Chesnais, 2005, p. 39)
} 
No âmbito da organização do trabalho assalariado, observa-se a tendência de reformas e medidas de austeridade à população em nome da manutenção da lógica econômica. A emergência de subempregos, terceirizados, subcontratados, com o advento de desempregados, faz parte do procedimento do Estado-finanças que precisa proteger o capital portador de juros, especulativo e destrutivo. Logo, a "culpa" recai sobre os indivíduos que possuem a força de trabalho e precisam vendê-la para sua própria sobrevivência, assumindo os riscos da falta de proteção social.

Para proteger o capital portador de juros, cuja engrenagem não poderia resultar em outro fato senão em crises no seu próprio sistema, as reservas públicas são solicitadas para suprir os devaneios do sistema financeiro com taxas de juros quase irrelevantes, ou seja, o Sistema da Dívida é alimentado por fraudes causadas pelo sistema que tem como base a especulação da hegemonia financeira ${ }^{8}$.

A demanda especulativa financeira ocasiona e aprofunda crises nos diversos setores da sociedade. Nesse sentido, o trabalho assalariado nas relações de financeirização reproduz e intensifica o processo de mais-valia, pois na lógica capitalista, o Estado exerce o poder regulador na relação capital e trabalho, logo, como detentor da hegemonia, exerce o consenso e a coerção estatal, sempre que necessário, para a manutenção das regras sociais existentes e a repartição desigual da riqueza socialmente produzida. Por isso, no contexto da financeirização, em nome da lógica do capital portador de juros, o trabalho assalariado é a fonte de subtração de regulações mínimas exercidas pelo próprio Estado, isso porque a mais-valia absoluta e relativa passa a atuar com base em valores relacionais ${ }^{9}$ para a acumulação perpétua do capital.

As várias formas de manifestação do capital, e aqui em destaque o capital financeiro, culmina no desenvolvimento de processos de informatização nas relações sociais. $\mathrm{O}$ avanço tecnológico é permeado pelo ininterrupto processo circular e destrutivo do desenvolvimento socioeconômico, uma vez que, com relação ao trabalho assalariado, a substituição ou mesmo a eliminação de postos de trabalho será cada vez mais recorrente. Como consequência, os trabalhadores humanamente descartáveis passam a ser empreendedores da própria sorte e responsáveis individualizados pela miserabilidade social e econômica em que vivem e enfrentam.

A eliminação de postos de trabalho causada pelo avanço da inteligência artificial ou desenvolvimento tecnológico não significa o sumiço ou inexistência do trabalho na lógica capitalista. Pelo contrário, significa a intensificação da precarização do trabalho assalariado à subserviência de condições em que há a falta de seguridade social, deixando a força produtiva humana à mercê da informalidade e da flexibilidade.

As circunstâncias laborais, com base na agudização do sistema financeiro, bem como a incorporação do avanço tecnológico, é um dos fatores que permite contraditoriamente o consenso e a dominação social de classes. Com isso, as práticas predatórias do sistema de especulação indicam uma nova configuração social sobre o trabalho assalariado mediante a introdução das tecnologias de informação e comunicação (TIC), que na verdade são potencializações da força de trabalho na forma de ciência e tecnologia, mas que por estarem subordinadas aos ditames do capital degradam as condições sociais e intensificam a exploração da força de trabalho.

A conjuntura atual do desenvolvimento tecnológico fundamenta a concepção de irrelevância humana perante às novas formas fictícias de capital. A descartabilidade humana passa a ser recorrente nas relações sociais do trabalho assalariado, uma vez que ocorre a sofisticação da vida social e das instituições que gerenciam os fluxos do capital portador de juros. Como consequência, a força humana produtiva é ameaçada constantemente pelas formas de expropriação, exploração e manipulação da força de trabalho necessária e descartável que o capital em suas configurações submete a todos. De acordo com Mészáros

\footnotetext{
${ }^{8}$ Dentre outros, ver Fatorelli M. L. (2019). O escândalo da remuneração diária da sobra de caixa. Associação dos Funcionários do Banco do Nordeste do Brasil. https://www.afbnb.com.br/artigo-o-escandalo-da-remuneracao-diaria-da-sobra-de-caixa/

9 “[...] Valores relacionais mudam com sentimentos, humores, confiança, expectativas e antecipações do mercado" (Harvey, 2018, p. 141).
} 
(2011b) estamos diante do desemprego como uma tendência crônica da crise estrutural do capital que atinge não só os países subdesenvolvidos, mas também os países centrais do desenvolvimento capitalista:

Portanto, não estamos mais diante dos subprodutos "normais" e voluntariamente aceitos do "crescimento e do desenvolvimento", mas de seu movimento em direção a um colpaso; nem tampouco diante de problemas periféricos dos "bolsões de subdesenvolvimento" mas diante de uma contradição fundamental do modo de produção capitalista como um todo, que transforma até mesmo as últimas conquistas do "desenvolvimento", da "racionalização" e da "modernização" em fardos paralisantes de subdesenvolvimento crônico. (Mészáros, 2011b, p. 69).

A dispensabilidade da força produtiva humana precisa ser incorporada como consenso pela população mundial. Os sobrantes desse sistema, guiados pelo Estado-finanças, assentem, mesmo sem a compreensão da totalidade das dimensões sociais do trabalho assalariado, com a produção ideológica de conformidade da classe hegemônica, advinda da divisão social do trabalho.

O consentimento ideológico é elemento chave do plano superestrutural da organização da cultura. No campo da ciência e da técnica, igualmente na divisão social do trabalho, processa-se o desenvolvimento de intelectuais nos seus diversos níveis e a escola é o principal instrumento de tais formações. Em síntese, “[...] quanto mais extensa for a 'área' escolar e quanto mais numerosos forem os 'graus' 'verticais' da escola, tão mais complexo será o mundo cultural, a civilização, de um determinado Estado." (Gramsci, 1982, p. 9).

Gramsci (1982) esclarece o paradigma da formação cultural na sociedade de classes. A "alta cultura" é destinada ao poder de uma classe sobre a outra, de modo a legitimar a ordem social vigente. Tendo em vista que a formação dos intelectuais é mediatizada pelo mundo da produção, a organicidade desses é fixada em gradações do plano da superestrutura: sociedade civil e Estado. ${ }^{10}$

A organização cultural na sociedade capitalista obedece à lógica Trabalho-Educação, isto é, a formação dos indivíduos converge com a noção de qualificação e adaptação humana às formas de sociabilidade que o capital adquire. Em cada período histórico do capital, exige-se uma formação adequada aos fins da razão socioeconômica. Não por acaso, a educação tem se tornado um grande negócio, uma vez que se configura como um processo sociocultural complexo de mediação técnicoprofissional, funcional e ideológica.

No Estado-finanças o poder hegemônico assume uma amplitude global, cujos princípios de formação humana são disseminados por Organismos Internacionais como a Organização das Nações Unidas para a Educação, a Ciência e a Cultura (UNESCO), Banco Mundial, Organização para a Cooperação e Desenvolvimento Econômico (OCDE), etc. Nesse contexto, a formação humana coincide com qualificação para o mercado de trabalho, portanto, a premissa Trabalho-Educação se torna o sustentáculo da Teoria do Capital Humano. A ideia central defendida por essa teoria, reitera o princípio do individualismo para a formação humana, com a pretensão de justificar as desigualdades socioeconômicas, políticas e culturais no indivíduo em si. Por isso, é comum na sociedade de classes a apologia de que os trabalhadores recebem um salário baixo por não terem investido no seu próprio capital humano ${ }^{11}$.

Grande parte das orientações e diretrizes dos Organismos Internacionais consideram a educação como fonte de provimento das contradições sociais. A circulação de capital com base no dinamismo do avanço tecnológico e das organizações financeiras, com ênfase nas parcerias público-privadas, anseiam da educação as competências do mundo globalizado. Nesse sentido, a Teoria do Capital Humano se adequa aos princípios necessários da sociabilidade do capital:

\footnotetext{
10 “[...] A sociedade civil é determinada pelas várias formas de organização social, na qual constituem o grupo dos dominantes versus dominados. Já a sociedade política ou Estado corresponde a função de hegemonia que o grupo dominante exerce em toda a sociedade (Gramsci, 1982), em outras palavras, são todas organizações representativas das forças que dominam e detém a hegemonia de classe.” (Autor, 2021, p. 58).

11 “[...] Não nos surpreende, portanto, que por razões ideológicas, e não por razões intelectuais sólidas, todas as grandes instituições do capital, das organizações econômicas ao Banco Mundial e ao FMI, tenham abraçado de corpo e alma essa ficção teórica”. (Harvey, 2016, p. 172).
} 
Para las personas físicas y las familias, la educación promueve el capital humano, mejora las oportunidades económicas, promueve la salud y aumenta la capacidad de tomar decisiones eficaces. Para las sociedades, la educación aumenta las oportunidades económicas, promueve la movilidad social y hace que las instituciones funcionen de manera más eficaz. (Banco Mundial, 2018, p. 27).

A Teoria do Capital Humano fundamenta e dá respaldo ao tipo de educação necessária em cada período histórico do capital. A premissa Trabalho-Educação é mantida e constantemente renovada para atender às expectativas do mercado econômico, assim, a partir da era tecnológica e flexível, a aprendizagem reiterada é aquela capaz de promover habilidades e conhecimentos considerados básicos para o futuro do trabalho:

El futuro del trabajo valorará el aprendizaje. El ritmo acelerado de los avances tecnológicos ha producido grandes cambios en la naturaleza del trabajo, y ha llevado a algunos a declarar que estamos viviendo una nueva era: La Segunda Edad de las Máquinas o la Cuarta Revolución Industrial. Las versiones extremas de esta visión indican que podrían desaparecer todos los empleos, salvo unos pocos, lo que disminuiría el valor de las habilidades para la mayoría de las personas. Sin embargo, los cambios sísmicos pronosticados aún no se han reflejado en los países de ingreso alto y mucho menos en los de ingreso bajo y mediano. Lo más importante es que, sin perjuicio de los cambios en la demanda de habilidades en el futuro, las personas necesitarán una base sólida de habilidades y conocimientos básicos. (Banco Mundial, 2018, p. 27. Grifo nosso).

O avanço tecnológico, conforme explicitado, tem promovido mudanças na natureza do trabalho, pois, segundo o Banco Mundial (2018), atualmente, vivencia-se a quarta Revolução Industrial. Para tanto, a aprendizagem para a promessa do futuro se orienta conforme o modus operandi do capital especulativo, que por sua vez está inserido na chamada quarta Revolução Industrial e se inscreve, consequentemente, no projeto educacional mundial alinhado aos ditames socioeconômicos e políticos da economia do conhecimento.

Para ser qualificado na economia do conhecimento, precisa-se da mobilização de competências do mundo globalizado que auxiliem a reprodução social. Nessa lógica, a preparação para o instável, volúvel e mutável se torna a diretriz norteadora para a educação global.

O poder ideológico da educação competente para o mundo globalizado é justamente o de internalizar nos indivíduos em forma de consenso a necessidade de expansão do capital como suas próprias necessidades reais. Com isso, observa-se que o Estado-finanças legitima, mediante uma organização cultural estratificada, a ortodoxia dominante e oculta os valores implícitos de suas consequências estruturais e sociais.

A noção de competência enquanto preparação humana para uma supremacia econômica, precisa produzir uma mistificação ideológica a fim de suprir os limites da própria teoria que enfatiza a qualificação para o mercado de trabalho. Isso porque, à medida que o capital financeiro avança sem limites e regulamentações disciplinadoras, torna-se comum crises no mercado especulativo com efeitos socioeconômicos e políticos para toda sociedade do mundo globalizado. Um dos efeitos paradoxais do avançado capital financeiro e seu consequente avanço tecnológico é o retrocesso da atividade humana produtora de valor que contraditoriamente gera a intensificação do processo da mais-valia absoluta, em particular, nas formas mais severas de degradação e espoliação do trabalho. Contradição inerente ao processo histórico de desenvolvimento do capital que os intelectuais orgânicos ${ }^{12}$ desse sistema tentam solucionar com medidas paliativas.

Uma das saídas gloriosas da insegurança financeira é buscar na educação o amparo ideológico desse sistema. Logo, economia do conhecimento ou o know-how da produtividade, ampara-se na representatividade do crescimento sustentável e harmonioso, em que economia e educação garantam a preparação para a instabilidade do século XXI. Na perspectiva do ensino de competências, estão as propostas de metodologias de aprendizagem ativas com a finalidade de formar um profissional

${ }^{12}$ De acordo com Gramsci (1982), existem diversas categorias de intelectuais e cada grupo social detém seus intelectuais que dão homogeneidade e consciência de sua própria função. 
inovador, e supostamente protagonista de sua aprendizagem (Moraes et al., 2021), isto pois, é possível observar a preocupação atual em aliar aprendizagem, tecnologia e emoções para a formação de trabalhadores empoderados que utilizem as emoções a seu favor (Ferreira et al., 2022).

A educação no século XXI se firma na busca pela adequação mercantil e concorrencial. Para consolidar ideologicamente o princípio da sociabilidade corrente, soluções privadas são designadas para garantir a suposta livre economia de mercado. O empreendedorismo na educação, como um dos ingredientes da Teoria do Capital Humano é almejado para justificar o fracasso ou ineficiência do ensino público por meio dos parâmetros educacionais das avaliações em larga escala.

Para suprir as insuficiências educacionais do ensino público, as Parcerias Público-Privadas (PPP) ${ }^{13}$ apresentam-se como uma ferramenta para o alcance da qualidade educacional pretendida nos parâmetros das avaliações em larga escala. As PPP atuam na modalidade contratual de concessão, o que em linhas gerais quer dizer que prestam um determinado serviço ao Estado com dinheiro público, ou seja, o Estado é o regulador e o setor privado o executor ${ }^{14}$. Além disso, embutida na PPP está o aspecto funcional e ideológico de todo o processo, acentuando o controle social e político da ordem social vigente.

Nessa concepção empreendedora de educação, o Estado é um mau gestor e atrapalha com sua ineficácia a concorrência do "livre mercado". É por isso que sucessivas reformas são feitas na área educacional com o objetivo de torná-la atrativa aos investimentos transnacionais. A lógica mercantil e concorrencial na educação tem como finalidade

[...] garantir o domínio de competências e habilidades necessárias para a atividade econômica revolucionada pelas novas tecnologias e processos de trabalho (Revolução 4.0) e, por outro, garantir que tal iniciativa se contenha dentro da sua visão de mundo que se traduz em um status quo modernizado. (Freitas, 2018, p. 42)

As competências e habilidades da conjuntura global com ênfase em tecnologias avançadas e um sistema financeiro permeado por sua volatilidade, tornam-se imprescindíveis para a sobrevivência no mundo versátil. Em nome do establishment da flexibilização, cuja dinâmica prevalecente se baseia em incertezas, competências socioemocionais são elementares na elevação de capital humano, bem como para a lógica sistêmica dos mecanismos refinados de expropriação e exploração.

As características valorativas do ser humano em formação são requisitos de sobrevivência para as consequências estruturais do capital portador de juros que funcionam como um aporte psicossocial e ideológico para a manutenção do controle social. Capacidades como autoconscientização, autorrealização, empatia, compaixão, interdependência, otimismo, confiança, devoção, abnegação, autodisciplina, espiritualidade, subordinação, engajamento, lealdade, flexibilidade, resiliência, etc., são mecanismos de eloquência e persuasão do próprio capital humano que precisa difundir nos indivíduos a necessidade de adequálos e subordiná-los aos aspectos socioeconômicos e financeiros do mundo global por meio de dispositivos de internalização ideológica dos processos sociais hegemônicos da ordem social vigente.

\section{Considerações Finais}

Na dinâmica do Estado-finanças, trabalho e educação se articulam aos princípios globais. Por isso, o conceito "TrabalhoEducação" é apresentado como efeito da demanda de "livre mercado" adotada pela política neoliberal. Entretanto, é imperativo destacar a atuação do Estado em salvaguardar o capital portador de juros na economia que tem como um dos princípios a não intervenção estatal. Como consequência, o que se observa é a acumulação sem precedentes, encaminhando-se para a incontrolabilidade e destrutividade do próprio sistema que busca personificações para a sustentar a lógica sociometabólica do capital globalizado.

\footnotetext{
${ }^{13}$ Trabalhamos com a ideia de Freitas (2018) de que não há "meia privatização" ou "quase mercado". Portanto, em essência, não há distinção entre "privatização" e "publicização".

${ }^{14}$ A partir da Reforma do Aparelho do Estado de 1995 brasileiro, adota-se os mecanismos do gerencialismo para a administração pública.
} 
Uma das personificações mistificadores é se utilizar da educação enquanto amparo ideológico do Estado-finanças. A internalização das perspectivas globais requer da educação a adoção de valores formativos adequados às formas de sociabilidade que o capital adquire. Vale ressaltar que educação por si só não consolida o sistema capitalista, porém, na sociedade de classes, consolida o consenso por meio da cultura.

A indissociável premissa do sistema capitalista "Trabalho-Educação" faz parte da essência da Teoria do Capital Humano que precisa difundir a lógica mercantil e concorrencial com o objetivo de manter o consentimento necessário aos indivíduos, além de subordiná-los a constantes adequações humanas aos fins socioeconômicos.

Para atender às expectativas de um sistema insaciável, reformas de austeridade fiscais são aplicadas em todos os setores da sociedade. Dentre elas, o trabalho assalariado torna-se fonte de dissoluções de proteções sociais mínimas aos trabalhadores, de modo que a informalidade se generaliza para assegurar a mistificação do avanço tecnológico, bem como o consenso e a dominação social de classes.

No Estado-finanças, em nome do "livre mercado" e para justificar a aparente ineficiência do bem público, as PPP simbolizam o suprassumo do ideário do desenvolvimento econômico. Assim, ao menos no plano formal, o setor privado passa a se encarregar pela execução dos recursos públicos com eficiência e eficácia. Na educação, as orientações e diretrizes dos organismos internacionais assentem para uma concepção empreendedora a partir de soluções privadas, no âmbito da gestão e dos processos educativos, para se adquirir capital humano.

A introdução de empreendimentos educacionais privados na gestão dos processos educativos, permite o controle dos processos educativos. É nesse sentido que os agentes educacionais empreendedores se comprometem com a agenda educacional da Teoria do Capital Humano.

Portanto, a indissociável premissa do sistema capitalista "Trabalho-Educação" estrutura a formação humana para as competências e habilidades necessárias à sobrevivência do modus operandi do capital portador de juros. Por isso, a "nova" investida dos empreendedores educacionais, alinhados a partir das orientações e diretrizes dos organismos internacionais, enfatiza a formação educativa com base em competências socioemocionais, haja vista que a formação valorativa dos indivíduos é capaz de resigná-los para as condições do trabalho assalariado cada vez mais flexível e precarizado

\section{Referências}

Antunes, R. (2020). Trabalho intermitente e uberização do trabalho no limiar da indústria 4.0. In Antunes, R. Uberização, Trabalho digital e indústria 4.0. (pp. 11-23). Boitempo.

Banco Mundial. (2018). Aprender para hacer realidade la promesa de la educación: Panorama general.

Chesnais, F. (2005). O capital portador de juros: acumulação, internacionalização, efeitos econômicos e políticos. In Chesnais, F. (Org.). A finança mundializada: raízes sociais e políticas, configuração, consequências (R. Marques \& P. Nakatani Trad.) (pp. 35-68). Boitempo.

Duménil, G., \& Lévy, D. (2005). O neoliberalismo sob a hegemonia norte-americana. In Chesnais, F. (Org.). A finança mundializada: raízes sociais e políticas, configuração, consequências (R. Marques \& P. Nakatani Trad.) (pp. 85-108). Boitempo.

Evangelista, O. (2012). Apontamentos para o trabalho com documentos de política educacional. In R. M. L. Araújo, \& D. S. Rodrigues (Orgs.). A pesquisa em trabalho, educação e políticas educacionais. 52-71. Alínea.

Fatorelli, M. L. (2013). Auditoria Cidadã da Dívida Pública: Experiências e Métodos. Inove Editora.

Fatorelli M. L. (2019). O escândalo da remuneração diária da sobra de caixa. Associação dos Funcionários do Banco do Nordeste do Brasil. https://www.afbnb.com.br/artigo-o-escandalo-da-remuneracao-diaria-da-sobra-de-caixa/

Ferreira, L. M., Carvalho, A. dos S. M. de, Guimarães Junior, J. C., Pereira, P. C., Conceição, J. L. M. da, Oliveira, E. dos S. M., Albuquerque, L. F. da S., \& Caboclo, I. (2022). Aprendizagem nos tempos atuais, tecnologia, emoções, pandemia. Research, Society and Development, 11(1), e27611124980. https://doi.org/10.33448/rsd-v11i1.24980

Freitas, L. C. de. (2018). A reforma empresarial da educação: nova direita, velhas ideias. Expressão Popular.

Gramsci, A. (1982). Os Intelectuais e a Organização da Cultura. (C. N. Coutinho, Trad.). Editora civilização Brasileira S.A. 
Research, Society and Development, v. 11, n. 2, e20411225609, 2022

(CC BY 4.0) | ISSN 2525-3409 | DOI: http://dx.doi.org/10.33448/rsd-v11i2.25609

Gonçalves, A. M. (2021). Os Intelectuais Orgânicos da Base Nacional Comum Curricular (BNCC). CRV.

Harvey, D. (2016). 17 contradições e o fim do capitalismo (R. Bettoni, Trad.). Boitempo.

Harvey, D. (2018). A loucura da razão econômica: Marx e o capital no século XXI (A. Renzo, Trad.). Boitempo.

Harvey, D. (2014). Para entender o capital: Livros II e III (R. Enderle, Trad.). Boitempo.

Mészáros, I. (2011a). Para além do capital. Boitempo.

Mészáros, I. (2011b). A crise estrutural do capital. Boitempo.

Millet, D.; Toussaint, É. (2006). 50 perguntas 50 respostas sobre a dívida, o FMI e o Banco Mundial. (N. Rodrigues Josse, Trad.). Boitempo.

Morais, I. B. de A., Vendrametto, O.., \& Carvalho, G. C. G. (2021). Formação de um profissional inovador com a utilização de metodologias de aprendizagem ativa: avaliação da intervenção. Research, Society and Development, 10(17), e119101724150. https://doi.org/10.33448/rsd-v10i17.24150

Ramos, M. N. (2001). A pedagogia das competências: autonomia ou adaptação? Cortez.

Severino, A. J. (2016). Metodologia do trabalho científico. Cortez Editora.

Shiroma, E. O.; Campos, R. C.; \& Garcia, R. M. C. (2005). Decifrar textos para compreender a política: subsídios teórico-metodológicos para análise de documentos. PERSPECTIVA, 23(02), 427-446. http://www.ced.ufsc.br/nucleos/nup/perspectiva.html

Vásquez, A. S. (2011). Filosofia da práxis. (M. Encarnación Moya, Trad.) Expressão Popular.

Williamson, J. (1991). What Washington means by policy reform. In Williamson, J. (ed.). Latin American: how much has happened? https://www.piie.com/commentary/speeches-papers/what-washington-means-policy-reform 